\title{
USO DA TEORIA DA AGÊNCIA EM PESQUISAS DE CONTABILIDADE GERENCIAL: PREMISSAS, LIMITAÇÕES E FORMULAÇÕES ALTERNATIVAS AOS SEUS PRESSUPOSTTOS
}

\author{
Rosenery Loureiro Lourenço
}

Fernanda Filgueiras Sauerbronn ${ }^{2}$

\begin{abstract}
Resumo: O objetivo deste artigo é propor uma reflexão sobre o uso da Teoria da Agência nas pesquisas em contabilidade e, mais especificamente, Contabilidade Gerencial no Brasil, traçando considerações a cerca de suas premissas e limitações, bem como apontando outras formulações teóricas para o conceito de agência. Inicialmente a discussão mostra que a Teoria da Contabilidade geralmente é utilizada em combinação com teorias de outras áreas - normalmente econômicas e gerenciais - para sustentar o estudo dos fenômenos contábeis financeiros e gerenciais. Depois de apresentar a Teoria da Agência e suas três vertentes fundamentadas na economia e elencar algumas das principais críticas, são apresentadas outras possibilidades sociológicas para o estudo da agência. Estas perspectivas sugerem novas formas de olhar para: (i) o agente e os elementos que influenciam e explicam a ação humana, (ii) as estruturas de poder, e (iii) os níveis de análise. Por fim, o artigo apresenta algumas características de pesquisas em Contabilidade Gerencial no Brasil que utilizam outras teorizações de agência para fundamentar suas investigações, ajustando a profundidade metodológica e o pluralismo teórico necessário para o estudo do fenômeno em Contabilidade Gerencial.
\end{abstract}

Palavras-chave: Teoria da agência. Teorias sociais. Contabilidade Gerencial. 


\title{
USE OF AGENCY THEORY IN MANAGEMENT ACCOUNTING RESEARCH: PREMISES, LIMITATIONS AND ALTERNATIVE FORMULATIONS TO THEIR ASSUMPTIONS
}

\begin{abstract}
This paper aims to propose a reflection on the use of Agency Theory in accounting research and, specifically in Management Accounting in Brazil, making considerations regarding its assumptions and limitations, also presenting alternative formulations to the concept of agency. Initially, the discussion shows that accounting theory is associated with theories from other areas - ordinarily form economics and management - to nourish the study of financial and management accounting phenomena. After presenting the Agency Theory and three approaches based on economy, as well as list some of the main criticisms, some sociological alternatives are presented to the study agency. These perspectives suggest new ways of looking at (i) the agent and the elements that influence and explain human action, (ii) the power structures and (iii) the levels of analysis. Lastly, the paper presents some researchs' characteristics of management accounting in Brazil based on outher perspectie to theorize agency to ground their research, adjusting its methodological depth and theoretical pluralism necessary to study the phenomenon in Management Accounting.
\end{abstract}

Keywords: Agency Theory. Social Theories. Management Accounting. 


\section{INTRODUÇÃO}

mbora alguns autores considerem difícil definir o que é teoria para as ciências sociais, Malmi e Granlund (2005, p.5) explicam que teoria pode ser compreendida como"um conjunto coerente de proposições utilizadas como princípios de explicações para uma classe de fenômenos assumidos, em toda uma vasta gama de casos específicos". Uma teorização consistente é, ao mesmo tempo, princípio e destino em pesquisas acadêmicas de qualidade, sendo critério fundamental para a divulgação de estudos em periódicos científicos, segundo Bogt e Helden (2012). Whetten (2003) destaca ser necessário que as pesquisas possuam uma consistente amarração teórica para as relações presentes nas observações, e tal amarração pode basear-se em uma ou múltiplas teorias, conforme Jackson (1999) e Modell (2010).

No contexto da contabilidade, Smith (2011) argumenta que as explicações que ajudam dar sentido à diversidade constituem uma teoria. Para se estudar um fenômeno várias teorias estarão disponíveis, por isso, testar teorias alternativas permite que o pesquisador possa estabelecer qual das teorias melhor explica os fatos estudados. Já Ahrens e Chapman (2006, p. 823) entendem teoria como "um conjunto orientador de conceitos explicativos, tais como, por exemplo, a Teoria da Agência, a Teoria Contingencial, a Teoria Institucional, a Teoria de Controle de Gestão ou o Interacionismo Simbólico". Tal conjunto de conceitos explicativos é aplicável tanto à contabilidade financeira quanto à gerencial.

Conforme Malmi e Granlundi (2005), a Contabilidade Gerencial (CG) utiliza-se especialmente de dois tipos de teorias: i) teorias com status de teoria; ii) teorias que não possuem status de teoria. $\mathrm{O}$ primeiro tipo diz respeito às teorias importadas de outras ciências sociais, principalmente, da psicologia e da economia (por exemplo, Teoria da Contingência, Teoria do Agente-Principal, Teoria de Economia da Informação, Teoria da Definição de Objetivo). Algumas destas teorias constituem-se em base para explicação de inúmeras questões, que não propriamente da CG, e são utilizadas pelos pesquisadores para explicar como a contabilidade está relacionada à obtenção de um melhor desempenho. $O$ segundo tipo de teoria usada pela CG - teorias sem status de teoria - diz respeito a constructos teóricos ou Teorias Normativas como, por exemplo, Custeio Baseado em Atividades, Balanced Scorecard, Custeio de Qualidade, Gerenciamento Baseado em Valor. Embora estes constructos não sejam considerados como uma teoria pelos pesquisadores em CG, eles descrevem como deveríamos fazer alguma coisa.

Davis, Menon e Morgan (1982, p. 315) discorrem que teóricos e profissionais da contabilidade observam os fenômenos sociais com base em suposições prévias, ou seja, suas visões da realidade são justificadas a partir de suas pressuposições. Estes autores argumentam que além de serem poderosas para formatar o entendimento da realidade, as suposições destes observadores do mundo social "têm influenciado consideravelmente a direção da teoria contábil e da prática".

Conjecturando sob os argumentos destes autores, é possível afirmar que, se as pressuposições utilizadas pelos pesquisadores para pesquisar agência considerarem apenas uma modalidade teórica de Teoria da Agência, estas escolhas darão um formato unidirecional à Teoria Contábil e à prática. Nesse sentido, considerando que a Teoria da Contabilidade normalmente está ligada com teorias de outras áreas para explicar os fenômenos contábeis financeiros e gerenciais (Smith, 2011; Malmi \& Granlund, 2005), parte-se de algumas perguntas para o desenvolvimento do presente estudo: Que teorias de outras 
áreas são utilizadas em pesquisas contábeis? Entre tais teorias, como a Teoria da Agência é utilizada pela contabilidade e, mais especificamente, pela Contabilidade Gerencial? Que outras teorizações sobre o conceito de agência poderiam ser exploradas? Na tentativa de delinear argumentos para estas perguntas, sem exaurir as possibilidades, o presente ensaio propõe uma reflexão considerando as perspectivas sociológicas para o estudo de agência em pesquisa contábil gerencial no Brasil.

\section{TEORIA DA CONTABILIDADE E TEORIAS NA CONTABILIDADE}

Em Teoria da Contabilidade, há preocupação com aspectos diretamente relacionados à formação e evolução patrimonial de uma entidade, isto é, reconhecimento, mensuração e evidenciação de receitas, despesas, ativos e passivos. Nesse sentido, Hendriksen e Van Breda (2007, p. 22) discutem dois aspectos que são de ordem fundamental na Teoria da Contabilidade. Primeiro,"as questões teóricas não são apenas uma questão de 'teoria"'. Os autores destacam que a teoria possui implicação prática para administradores, auditores e outros agentes relacionados à contabilidade, exemplo disso é o reconhecimento ou não de receitas ou despesas, as quais impactam no faturamento e resultados, que impactam na obtenção de empréstimos, e também impactam na decisão de investidores e assim por diante.

Segundo, a Teoria da Contabilidade depende de julgamentos profissionais, tanto dos órgãos reguladores quanto dos profissionais no nível local, de maneira que "as questões teóricas raramente são dirimidas de maneira completa pelas autoridades contábeis" (Hendriksen \&Van Breda, 2007). Desta forma, as questões contábeis acabam por serem resolvidas em dois níveis, ainda que conselhos e organismos reguladores exijam divulgação contábil dentro de determinados parâmetros, no nível de empresa as escolhas individuais redundarão na aplicação de determinado padrão de diferentes maneiras.

De acordo com Hendriksen e Van Breda (2007, p. 32), a Teoria da Contabilidade "concentra-se num conjunto de princípios subjacentes e, presumivelmente, fundamentais para a prática contábil". De uma maneira mais formal, os autores definem a Teoria da Contabilidade como "um conjunto coerente de princípios hipotéticos, conceituais e pragmáticos que formam um quadro geral de referência para a investigação da natureza da contabilidade". Por esta definição esta teoria serve: i) como quadro de referência para avaliar as práticas contábeis; ii) como quadro de referência dentro do qual a prática pode ser explicada e prevista. Os autores também reconhecem que a prática contábil está sujeita a inúmeras forças, nesse sentido, princípios contábeis consistem em apenas uma destas forças moldadoras da prática.

"A distinção fundamental subjacente da Teoria da Contabilidade é aquela entre a Teoria Normativa (o que deveria ser) e a Teoria Positiva (do que é ou será)" (Smith, 2011, p. 36). Em ambas as classificações Teoria Descritiva (Positiva) ou Teoria Prescritiva (Normativa) - a teoria pode adotar um raciocínio indutivo ou dedutivo. Questões normativas (qual "a melhor maneira de registrar contabilmente uma transação?") e questões positivas ("como administradores e outros indivíduos decidem o que é melhor para eles?") juntas representam o campo da Teoria da Contabilidade (Hendriksen \& Van Breda, 2007, p.29-30). A Teoria da Contabilidade por meio do método dedutivo hipotetiza a respeito do mundo contábil e prescreve como a contabilidade deveria ser "para maximizar a utilidade da informação" para os usuários. A Teoria Positiva da Contabilidade visa estabelecer hipóteses e testá-las por meio de métodos quantitativos, com vistas a compreender como o mundo contábil realmente é (ludícibus, Martins \& Carvalho, 2005, p.16).

A Teoria Positiva da Contabilidade, segundo Beattie (2002), é sinônimo de uma forma extrema de empirismo em contabilidade, especialmente no contexto norte americano. Seus precursores e expoentes são os pesquisadores Ross Watts e Jerold Zimmerman para os quais os estudos normativos não se cons- 
tituem teoria científica. O foco de pesquisa positiva concentra-se especialmente em escolhas contábeis, gerenciamento de resultados e disclosure voluntário. O significante desenvolvimento da Teoria Positiva da Contabilidade está amplamente ligado à Teoria Econômica Neoclássica e à Teoria da Agência.

Watts e Zimmerman (1979, p. 276) discorrem que os custos de agência surgem porque os interesses dos gerentes (agentes) não coincidem com os interesses dos acionistas e partes interessadas (principais), e o equilíbrio ocorre "quando os custos líquidos de um relacionamento de agência, os custos de agência, são minimizados pelo trading-off nas diminuições da utilidade devida para a perda residual". Para estes autores as teorias da contabilidade possuem três funções em uma economia não regulamentada, atender a: demanda pedagógica, demanda informacional e demanda de justificação. A primeira função diz respeito a redução dos contratos de custos de agência, por meio de procedimentos contábeis diversificados. A função informacional refere-se à predição dos efeitos de procedimentos contábeis e como as escolhas contábeis afetam os custos de agência. A terceira função diz respeito a forma como a contabilidade pode servir aos próprios interesses de gerentes, e como ocorrem manipulações de lucros, etc. Em uma economia regulada, segundo os autores, as teorias da contabilidade ocupam função nos processos políticos de organismos de legislação de interesses especiais que possuem um papel de transferência de riquezas, e também nas regras e regulamentações governamentais. Nessa esfera, "políticos e burocratas responsáveis por promover o bem-estar geral buscam testemunho do interesse público não só para informá-los sobre os trade-offs, mas também para justificar suas ações para a imprensa e seus eleitorados" (Watts \& Zimmerman, 1979, p. 2282). Em seu estudo, esses autores advogam que as práticas e as teorias de contabilidade são afetadas pela intervenção governamental.

Diversos enfoques são aplicados à Teoria da Contabilidade para resolver problemas contábeis, entre eles, fiscal, legal, ético, econômico, comportamental e estrutural. O enfoque social e institucional, normalmente referido como abordagem social ou sociológica tem sido um enfoque desafiador para a análise de problemas contábeis (Hendriksen \& Van Breda, 2007), e têm recebido evidência nos últimos anos no Brasil (ludícibus, Martins \& Carvalho, 2005).

Smith $(2011$, p.1) inicia uma discussão na qual os pesquisadores em contabilidade são"descritos por muitos autores como 'parasitas' que se aproveitam do trabalho dos outros para gerar suas conclusões" e argumenta que, embora o termo seja exagerado, contém alguma verdade quando se pondera sob três aspectos: i) a pesquisa contábil possui uma pequena teoria própria, sua fonte teórica é proveniente de outras disciplinas, como economia, finanças, psicologia e comportamento organizacional; ii) os métodos de pesquisa em contabilidade são todos adaptados das ciências naturais e sociais; iii) poucos instrumentos de pesquisa são próprios da contabilidade, boa parte deles é originado ou adaptado da literatura organizacional.

A discussão em torno de ter pouca teoria própria e utilizar-se majoritariamente de teorias de outras áreas também faz parte das preocupações externalizadas por Malmi e Granlund (2005, p. 7). Estes autores defendem que "precisamos de teorias exclusivas de Contabilidade Gerencial", pois as teorias emprestadas de outras áreas quando aplicadas à CG têm oferecido pouco conhecimento das questões práticas, de forma que "um conjunto de teorias exclusivas de CG seria mais útil para as preocupações dos profissionais do que tem sido as teorias atuais utilizadas pelos pesquisadores contábeis gerenciais". Nesse sentido, não uma, mas um conjunto de teorias de CG "deveriam explicar a forma, o uso e as mudanças da contabilidade e dos métodos de controle em uma gama de circunstâncias" (Malmi \& Granlund, 2005, p. 12).

Smith (2011) e Laughlin (1995) destacam a importância de pesquisadores contábeis reconhecerem sua dependência de outras disciplinas e estarem conscientes dos métodos de pesquisa alternativos, 
bem como das teorias disponíveis para explanação e/ou previsão dos problemas contábeis. Assim, as escolhas contábeis podem ser estudadas não apenas a partir do raciocínio dedutivo e indutivo, mas também sob lentes interpretativas e críticas (Lourenço \& Sauerbronn, 2015). A Tabela 1 evidencia as as teorias mais influentes na área contábil

Tabela 1: Áreas de Conhecimento e Teorias influentes nas pesquisas em contabilidade

\begin{tabular}{|c|c|c|c|c|}
\hline Comportamento Organizacional & Economia & Finanças & Psicologia & Sociologia \\
\hline $\begin{array}{l}\text { * Teoria da Contingência (Argyris, } \\
\text { 1952; Becker \& Green, 1962). } \\
\text { * Teoria da Percepção própria } \\
\text { (Bem, 1972) } \\
\text { *Teoria dos Stakeholders } \\
\text { (Freeman, 1984). }\end{array}$ & $\begin{array}{l}\text { * Teoria dos Contratos (Watts } \\
\text { \& Zimmermman,1978). } \\
\text { * Teoria dos Custos de } \\
\text { transação (Coase, 1937; } \\
\text { Williamson, 1979). } \\
\text { * Teoria da Legitimidade } \\
\text { (contratos sociais de Platão e } \\
\text { Tomas Hobbes). } \\
\text { * Teoria da Sinalização } \\
\text { (Spence, 1973) }\end{array}$ & $\begin{array}{l}\text { *Teoria da Agência } \\
\text { (Jensen \& Meckling, } \\
\text { 1976). } \\
\text { * Teoria da estrutura de } \\
\text { Capitais (Modigliani \& } \\
\text { Muller, 1958). }\end{array}$ & $\begin{array}{l}\text { * Teoria dos Prospectos } \\
\text { (Kahnemann \& Tversky, } \\
\text { 1972). } \\
\text { * Teoria da Dissonância } \\
\text { Cognitiva (Festinger, } \\
\text { 1957). } \\
\text { Teoria da Atribuição } \\
\text { (Kelley, 1972) }\end{array}$ & $\begin{array}{l}\text { * Teoria da Aprendizagem } \\
\text { Social (Bandura, 1977). } \\
\text { * Teoria da Estruturação } \\
\text { (Giddens, 1984). } \\
\text { * Teoria Network-actor } \\
\text { (Callon, 1986; Latour, } \\
\text { 1986) }\end{array}$ \\
\hline
\end{tabular}

Fonte: Adaptada de Smith (2011) e Ryan, Scapens e Theobold (2002)

É importante destacar que este rol de teorias não esgota as possibilidades existentes, apenas representa as teorias mais influentes na trajetória de pesquisas em contabilidade financeira e gerencial, sendo que de maneira particular, "Teoria da Agência, Teoria da Sinalização, Teoria dos Stakeholders, Teoria da Legitimação, Teorias Institucionais e Teorias Sociológicas" são as teorias mais amplamente utilizadas (Smith, 2011, p. 41).

A pesquisa em contabilidade, tanto financeira quanto gerencial, encontra especialmente na Teoria da Agência, aplicada dentro de uma concepção econômica, uma forte expressão em artigos e teses doutorais (Rayan et al., 2002; Smith, 2011). Segundo Lambert (2007, p. 247), a Teoria da Agência "tem sido um dos paradigmas teóricos mais importantes da contabilidade durante os últimos 25 anos". Lambert (2007, p. 247) argumenta que a atratividade desta teoria para os pesquisadores em contabilidade reside no fato de ela permitir que os modelos incorporem "conflitos de interesse, problemas de incentivo e mecanismos de controle".

Fundamentalmente, conforme sintetiza Lambert (2007), a Teoria da Agência permite que os pesquisadores em contabilidade estudem a relação entre os problemas de incentivo, as informações contábeis e os sistemas de compensação.

Em termos de CG, uma importante contribuição oferecida pela Teoria da Agência é melhorar suas habilidades de modelagem matemática (Wawero, 2010, p. 170). A pesquisa contemporânea em Contabilidade Gerencial e a compreensão dos Sistemas de Controle Gerencial têm recebido significativos insights da Teoria da Agência (Chendall, 2007, p.166).

A perspectiva econômica da Teoria da Agência tem oferecido importantes contribuições, e entre suas aplicações para a Contabilidade Gerencial destacam-se: i) orçamento de capital; ii) agregação de medidas de desempenho; iii) controlabilidade do desempenho e avaliação do desempenho relativo; iv) uso de medidas não financeiras; v) medidas de performance adicional; vi) transferências de preços e limites da firma; vii) alocação de custos (Bromwich, 2007, p.155).

\section{TEORIA DA AGÊNCIA SOB A PERSPECTIVA ECONÔMICA: PREMISSAS E CRÍTICAS}

"Uma relação de agência existe quando um ou mais indivíduos (chamados de principais) contratam outras pessoas (chamadas de agentes), a fim de delegar responsabilidades a eles" (Baiman, 1990, p. 342). De acordo com Baiman (1990), principal e agente especificarão por meio de contratos de relação de 
trabalho diversos termos, como remuneração, função, direitos de propriedade, e sistemas de informação. No que se refere à Teoria da Agência, Baiman (1990, p. 341) destaca que a literatura enfatiza especialmente três vertentes: i) literatura principal-agente; ii) literatura econômica de custos de transação; iii) literatura Rochester delineada sobre o trabalho de Jensen e Meckling (1976) e a teoria positiva da contabilidade de Watts e Zimmermann (1986).

Essas três vertentes na Teoria da Agência assumem que os indivíduos são motivados por seus próprios interesses. A ação autointeressada e o comportamento oportunístico ocorrem em função de preferências e crenças específicas. Nesse sentido, um problema de agência surge quando o comportamento cooperativo que poderia maximizar o bem estar coletivo não é compatível com o interesse próprio de cada indivíduo, caso em que surge a perda de eficiência. As três vertentes assumem ainda que os gerentes além de agirem em interesse próprio respondem aos incentivos contidos nos contratos de trabalho (Baiman, 1990).

No contexto da Contabilidade Gerencial, como destaca Ogden (1993, p.182-183), as pesquisas partem do princípio de que os gerentes são tidos como motivados pelos próprios interesses e nunca perseguirão desinteressadamente os interesses dos proprietários de recursos econômicos, por quem foram contratados para agir em seu favor. Como estes proprietários não possuem as mesmas informações que estão à disposição dos gerentes, então: eles estão inaptos para observar diretamente o comportamento do gerente; eles não podem considerar unicamente medidas de desempenho para inferir o comportamento dos gerentes, pois elas não refletem com precisão a contribuição específica do gerente. A incerteza sobre como os resultados se relacionam às entradas envolve o grau de discrição do gerente que pode ser utilizado em benefício próprio. Nesse sentido, dado que a Teoria da Agência se concentra nas soluções para os problemas dos proprietários - levar os gestores a agir de acordo com os interesses dos proprietários via contratos de emprego - pesquisadores em Contabilidade Gerencial podem se concentrar em prescrever contratos de incentivo (Ogden, 1993).

Sob um paradigma econômico, as três vertentes descritas por Baiman (1990) apresentam estruturas similares para a análise das interações principal-agente, das razões para a perda de eficiência e dos processos de controle para tal perda. As diferenças entre as vertentes se acentuam especialmente quanto às hipóteses explicativas para o comportamento do agente e para a função dos sistemas de incentivos (Baiman, 1990).

A vertente Principal-Agente é a mais explorada em CG (Baiman, 1990; Lambert, 2007). A priori, defende-se que a Teoria da Agência no modelo principal-agente pode ser utilizada em qualquer situação onde um principal contrate um agente para agir em seu favor mediante sistemas de incentivo (Ogden, 1992:181).

Alguns autores destacam que uma importante crítica sobre a utilização da Teoria da Agência em CG está no fato de o modelo buscar uma solução ótima e equilíbrio para os objetivos. Nesse sentido, Burns e Scapens (2000) argumentam que, "embora essa abordagem possa ser capaz de sugerir novas técnicas, ela não contribui para nosso entendimento de como essas técnicas devem ser usadas nas organizações, ou a natureza da resistência à sua utilização". Outra crítica à Teoria da Agência pode ser circunscrita em termos de considerar a assimetria como um fenômeno unilateral e ignorar que o principal também possui informações não conhecidas pelo agente antes de firmar o conbtrato de trabalho (Wawero, 2010). A Tabela 2 mostra algumas características das vertentes econômicas na Teoria da Agência. 


\begin{tabular}{|c|c|c|c|}
\hline & Principal-agente & Custos de Transação & O modelo Rochester \\
\hline O indivíduo & $\begin{array}{l}\text { - Racional; } \\
\text { - Capacidade computacional } \\
\text { ilimitada; } \\
\text { - Capaz de antecipar e avaliar } \\
\text { contingências futuras. }\end{array}$ & $\begin{array}{l}\text { - Racionalidade limitada; } \\
\text { - Capacidade computacional } \\
\text { limitada; } \\
\text { - Contingências futuras não } \\
\text { podem ser todas previstas e nem } \\
\text { incorporadas nos contratos }\end{array}$ & $\begin{array}{l}\text { - Racionalidade limitada; } \\
\text { - Capacidade computacional } \\
\quad \text { limitada; } \\
\text { - Contingências futuras não } \\
\text { podem ser todas previstas e nem } \\
\text { incorporadas nos contratos. }\end{array}$ \\
\hline Os contratos & $\begin{array}{l}\text { - São abrangentes, completos e } \\
\text { sem custo; } \\
\text { - Os contratos são precisamente } \\
\text { aplicados; } \\
\text { - São aplicados contratos } \\
\text { previamente acordados, mesmo } \\
\text { que as partes renegociem-no } \\
\text { futuramente. }\end{array}$ & $\begin{array}{l}\text { - São incompletos e } \\
\text { imperfeitamente aplicados; } \\
\text { - Contingências previsíveis podem, } \\
\text { por opçăo, não ser incorporadas } \\
\text { aos contratos. }\end{array}$ & $\begin{array}{l}\text { - São incompletos, mas são ótimos } \\
\text { dados os custos de transaçãa; } \\
\text { - Contingências previsíveis podem, } \\
\text { por opçâo, não ser incorporadas aos } \\
\text { contratos; } \\
\text { - Mercados de capitais são eficientes } \\
\text { e antecipam os incentivos de gestão; }\end{array}$ \\
\hline $\begin{array}{c}\text { Razão para divergências entre o } \\
\text { comportamento cooperativo e } \\
\text { autointeressado }\end{array}$ & $\begin{array}{l}\text { O agente, que tem aversão } \\
\text { ao trabalho e ao risco, possui } \\
\text { informaçôes privativas que o } \\
\text { principal não acessa sem custo: } \\
\text { - Assimetria de informação } \\
\text {-Aversão ao risco do agente. } \\
\text { Solução cooperativa pode ser } \\
\text { possível. }\end{array}$ & $\begin{array}{l}\text { ' O surgimento de um evento não } \\
\text { contratado, em condições que o } \\
\text { mercado permita, ex explorado por } \\
\text { cada parte oportunisticamente: } \\
\text { - racionalidade limitada; contratos } \\
\text { dispendiosos com aplicação } \\
\text { imperfeita. } \\
\text { Solução cooperativa pode não ser } \\
\text { possível }\end{array}$ & $\begin{array}{l}\text { Custos de transação resultam em } \\
\text { uso de contratos incompletos e } \\
\text { comportamento oportunístico os } \\
\text { quais inibem a solução cooperativa } \\
\text { e favorecem o comportamento } \\
\text { autointeressado }\end{array}$ \\
\hline Foco das pesquisas em CG & $\begin{array}{l}\text {-Se concentra nas relações } \\
\text { contratuais entre indivíduos; } \\
\text {-Busca entender como surge o } \\
\text { problema de agência e como } \\
\text { pode ser mitigado por design } \\
\text { contratual/organizacional; } \\
\text { - Enfatiza a modelagem formal } \\
\text { do ambiente e a busca de uma } \\
\text { solução ótima } \\
\text { - Estuda o papel desempenhado } \\
\text { e a demanda por procedimentos } \\
\text { e processos dentro da firma, } \\
\text { como por exemplo, sistemas de } \\
\text { monitoramento, de orçamento, } \\
\text { de alocação de custos, de preços } \\
\text { de transferência, e como tais } \\
\text { sistemas podem mitigar os } \\
\text { problemas de agência. }\end{array}$ & $\begin{array}{l}\text { - Se concentra nas relações } \\
\text { contratuais entre as firmas; } \\
\text { - Enfatiza o teste empírico das } \\
\text { hipóteses explicativas para as } \\
\text { relações contratuais entre as } \\
\text { firmas; } \\
\text { - Enfatiza as relações de trabalho } \\
\text { auto-impostas; } \\
\text { - Enfatiza custos de transação e } \\
\text { comportamento oportunista; } \\
\text { - Estuda como os procedimentos } \\
\text { de governança e as relações } \\
\text { entre as firmas limitam o } \\
\text { comportamento oportunístico e } \\
\text { afetam investimentos em ativos de } \\
\text { relacionamento específico. }\end{array}$ & $\begin{array}{c}\text {-Busca entender como surge o } \\
\text { problema de agência e como pode } \\
\text { ser mitigado por design contratual/ } \\
\text { organizacional; } \\
\text { - Enfatiza custos de transação e } \\
\text { comportamento oportunista; } \\
\text { - Trabalha com modelos menos } \\
\text { formais e enfatiza o teste empírico } \\
\text { das hipóteses explicativas entre as } \\
\text { relações contratuais; } \\
\text { - Estuda os incentivos enfrentados } \\
\text { pelas partes contratantes e que } \\
\text { fatores poderiam ter originado os } \\
\text { contratos observados. }\end{array}$ \\
\hline Contribuição para a CG & $\begin{array}{l}\text { Fornecer um quadro coerente e } \\
\text { útil para: } \\
\text { - apreciar o papel dos } \\
\text { procedimentos de CG; } \\
\text { - compreender a demanda } \\
\text { e o efeito das políticas e } \\
\text { procedimentos de CG }\end{array}$ & $\begin{array}{l}\text { Embora permita compreender } \\
\text { a evolução dos procedimentos } \\
\text { de CG, este modelo não teve um } \\
\text { efeito significativo por não ter sido } \\
\text { aplicada a questões específicas } \\
\text { de CG. }\end{array}$ & $\begin{array}{c}\text { - Enquadrar agência em questões } \\
\text { de controle gerencial e escolhas } \\
\text { contábil-financeiras; } \\
\text {-identificar regularidades no } \\
\text { comportamento gerencial e } \\
\text { compensação de executivos. }\end{array}$ \\
\hline
\end{tabular}

Fonte: Elaborado a partir de Baiman (1990, p. 342-350)

$\mathrm{Na}$ argumentação de Baiman (1990, p.344-345) as críticas à vertente principal-agente podem ser compreendidas a partir de pelo menos três conjuntos: i) realismo de alguns dos pressupostos subjacentes - no custo dos contratos, por exemplo, critica-se a premissa de que os contratos serão cumpridos mesmo que as partes queiram recontratá-los; ii) simplicidade do modelo - critica-se que a ênfase nas soluções ótimas e ambiente interno consistente restringe a modelos simples que não consideram o ambiente sob uma visão ampliada. Nas modelagens frequentemente são ignoradas as relações entre contratos ótimos e mercados de produtos e trabalho, além de ignorar o efeito do mercado de capitais; iii) os resultados da vertente principal-agente - critica-se que oferece pouco conhecimento da forma e conteúdo dos contratos analisados, observa-se formas contratuais simples e complexas na realidade, mas o modelo enfatiza sobre consistência interna, otimização e racionalidade, há um modelo simplificado com soluções complexas.

De acordo com Ogden (1993, p. 182), também consiste em uma "formidável barreira" para que a Teoria da Agência seja estendida a problemas mais complexos, o fato de que exige sofisticadas requisições matemáticas para analisar os mais básicos problemas de agência. Ogden (1993, p. 180) considera ainda que a Teoria da Agência "é incapaz de lidar adequadamente com as complexidades e as contradições em torno dos usos da informação contábil encontrada na gestão, avaliação e controle de desempenho dos empregados". 
A principal crítica que Ogden (1993) endereça à Teoria da Agência está em termos da não exploração das relações de poder, pois como destaca o autor, os pesquisadores "não consideram as estruturas de poder dentro das quais a atividade organizacional é situada, nem como as relações de poder entre empregadores e empregados determinam e sustentam negociações particulares resultantes de contratos negociados" (Ogden, 1993, p. 184).

Ogden (1993) defende que a compreensão aprofundada - quer seja da relação proprietário-gerente (que vê a solução nos incentivos financeiros), quer seja da relação gerente-trabalhador (que vê os incentivos financeiros como apenas um tipo de solução) -, não pode se furtar ao entendimento das relações de poder envolvidas e o seu contexto.

A não exploração do contexto mais amplo que envolve a relação principal-agente também recebe críticas por parte de Wiseman, Cuevas-Rodríguez e Gomez-Mejia (2012, p. 205). Para estes autores, o fato de muitas pesquisas baseadas na Teoria da Agência se concentrarem no design eficiente dos contratos e se direcionarem por uma "visão calculativa nas transações entre agente e principal", resulta em falhas em termos de oferecer uma compreensão da matriz social ampla em torno da criação destes contratos. Considerar o contexto social se torna importante, pois tal contexto define a natureza dos contratos, possui elementos nem sempre calculáveis com facilidade - por exemplo, reputação, satisfação pessoal, vergonha, confiança - e pode melhorar o entendimento de como os agentes respondem a ele.

Wiseman, Cuevas-Rodríguez e Gomez-Mejia (2012, p. 205) argumentam ainda que pesquisas sobre a Teoria de Agência que são desenvolvidas com base no modelo de Jensen e Meckling (1976) falham ao negligenciar o"fato de que as transações são socialmente construídas e desta forma ignoram as implicações derivadas do reconhecimento formal de que estas transações residem dentro de um contexto institucional amplo". No entanto, estes autores afirmam que, tais falhas não restringem definitivamente a aplicabilidade da teoria, mas deveriam ser visualizadas como uma oportunidade para que estas perspectivas fossem incorporadas à teoria.

\section{OUTRAS POSSIBILIDADES: AGÊNCIA SOB AS LENTES DE} TEORIAS SOCIAIS

Embora a Teoria da Agência tenha apresentado diversas contribuições ao longo das últimas três décadas, as críticas de igual modo se avolumaram especialmente ao redor dos pressupostos fundamentados sobre algumas características essenciais da economia neoclássica (Baiman, 1990; Ogden, 1992; Burns \& Scapens, 2000; Wawero, 2010). Surgem então alguns estudos que convidam a repensar a Teoria da Agência, e oferecem um novo prisma para abordar agência, entre os quais podem ser citados, por exemplo, os trabalhos de Wiseman, Cuevas-Rodríguez \& Gomez-Mejia (2012) que propõem uma abordagem sociológica para a Teoria da Agência; Sauerbronn \& Faria (2012) que propõem a contabilidade sobre uma perspectiva de prática social em adição à co-determinação de ação.

Wiseman, Cuevas-Rodríguez e Gomez-Mejia (2012) sugerem que conceitos chaves sejam ampliados e as limitações apontadas por críticos para aplicar a teoria sejam substituídas por uma perspectiva institucional. Desta forma, abandonando a caracterização extrema de comportamento oportunístico do agente, por exemplo, e substituindo-o por um conceito amplo e flexível, estes autores acreditam que a Teoria da Agência possa ser utilizada como ferramenta analítica para qualquer fenômeno de delegação, qualquer que seja o contexto. A proposta dos autores é que a teoria passe a considerar que o conflito 
de interesse entre principal e agente seja uma possibilidade, pois ambos podem ter objetivos que são ocultos ao outro: "Desta perspectiva, convergência e divergência de interesse é um processo dinâmico desde que as partes possam concordar ou discordar sobre questões chaves de diferentes pontos de seus relacionamentos" (Wiseman, Cuevas-Rodríguez \& Gomez-Mejia, 2012, p. 204).

Estes autores conceituam alguns termos chaves sob nova concepção. Para Wiseman, Cuevas-Rodríguez e Gomez-Mejia (2012, p. 204), problemas de agência referem-se a "disponibilidade de informação limitada, metas idiossincráticas independentemente escondidas pelo principal e agente que, em combinação, produzem o potencial para comportamento oportunístico incluindo risco moral e seleção adversa". Ao relaxar a noção de autointeresse dos modelos econômicos, estes autores alegam que tanto agente quanto principal, agora nomeados indivíduos, tem interesses socialmente derivados que podem ou não ser coincidentes.

Desta forma, a Teoria da Agência passa a requerer apenas o reconhecimento de que existe potencial diferença entre interesses, e como existem informações assimétricas entre o principal e agente e seu relacionamento além de ser de natureza dinâmica também é de longo prazo, o principal teria dificuldades em perceber que o agente possui interesses diferentes dos seus, razão pela qual mecanismos de governança tornam-se necessários. A este respeito os autores argumentam que a necessidade de governança não é em decorrência de agentes universalmente autointeressados, mas em função da dificuldade de os principais saberem quando o interesse próprio do agente ocorre ou não, e porque os agentes poderiam "interpretar o que é melhor para a organização de uma maneira diferente do principal" (Wiseman, Cuevas-Rodríguez \& Gomez-Mejia, 2012, p.204).

Sob a argumentação de que a governança varia de acordo com os contextos sociais, Wiseman, Cuevas-Rodríguez \& Gomez-Mejia (2012) propõem uma teorização de agência mais socializada, conforme mostra a Figura 1. Nesse sentido, consideram que mecanismos sociais (instituição, cognição, redes de trabalho e poder) influenciam convenções de uma sociedade e definem os papéis do principal e do agente. Os mecanismos permitem identificar aspectos dos papéis e interesses dos indivíduos na sociedade e a natureza dos problemas surgidos a partir de sua interação.

Figura 1: Contextos institucionais e seus efeitos sobre os problemas de agência e investimentos em mecanismos de

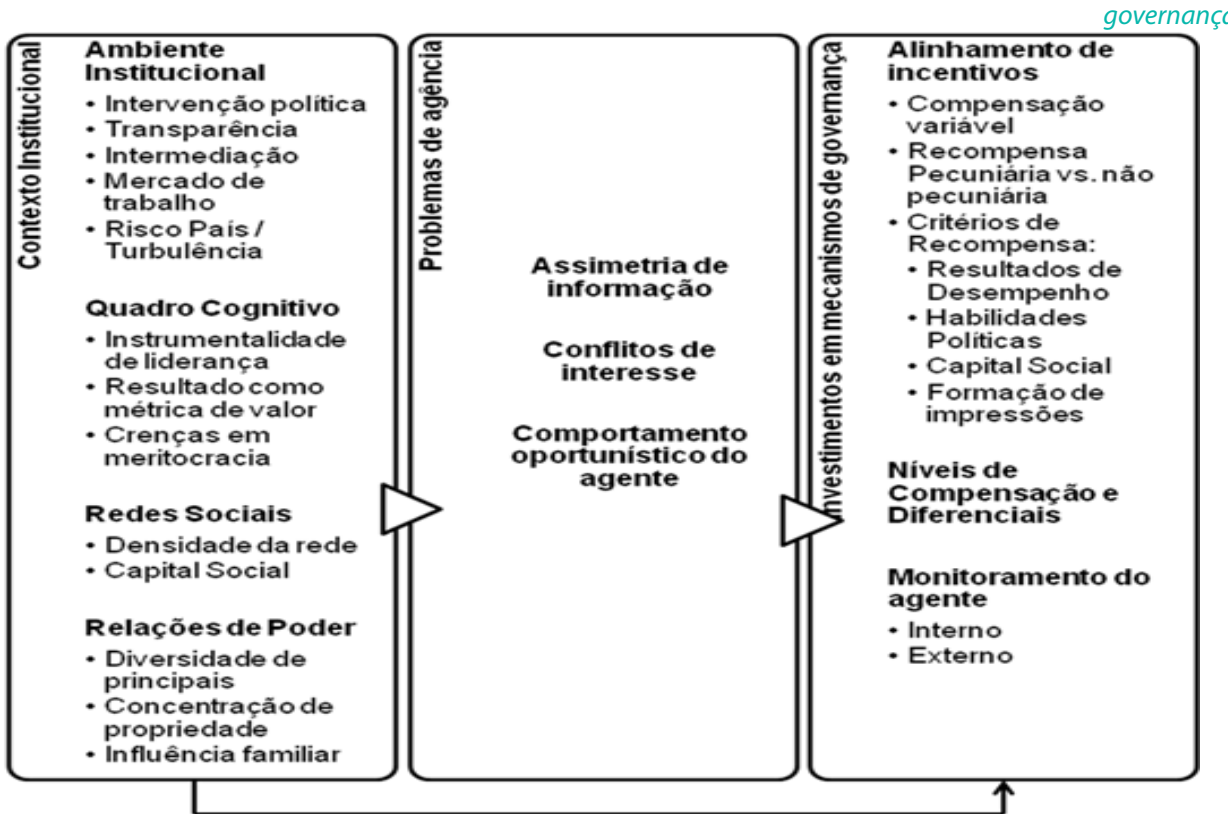

Fonte: Wiseman, Cuevas-Rodríguez \& Gomez-Mejia (2012, p. 206) 
Os ambientes institucionais moldam a natureza dos problemas de agência. Estes, por sua vez, expressos na assimetria de informação, conflito de interesses e comportamento oportunista, são universais. Os incentivos não são apenas de ordem financeira, podem ser socioemocionais, por exemplo.

Wiseman, Cuevas-Rodríguez \& Gomez-Mejia (2012, p. 207) defendem o desenvolvimento de uma Teoria Social da Agência. Para estes autores, este seria"um primeiro passo para a compreensão de como as relações P-A podem variar entre os contextos sociais, que por sua vez pode variar entre e dentro das fronteiras nacionais".

Outra perspectiva para estudar agência é oferecida por Sauerbronn e Faria (2012). Estes autores discorrem sobre como especificamente dentro do contexto brasileiro a pesquisa em contabilidade sob a perspectiva econômica da Teoria da Agência tem inibido o avanço da teorização em agência, avanço este já experimentado por países que estudam a contabilidade como prática social.

Pesquisas e desenvolvimentos teóricos em contabilidade no Brasil "privilegiam o controle do oportunismo gerencial, a redução da assimetria de informações por meio da ampliação do monitoramento e, finalmente, o alinhamento de interesses" como dita a TA, e sob esta perspectiva as ações humanas que ultrapassam os interesses pessoais do agente, a racionalidade e a aversão ao risco acabam por ser desconsideradas (Sauerbronn \& Faria, 2012, p. 4).

Para acessar aspectos da ação que não podem ser abordadas pela TA, em função dos seus pressupostos teóricos, Sauerbronn e Faria (2012) recomendam que pesquisas sobre agência reconheçam a contabilidade como"um conjunto de práticas sociais [que constituem e são constituídas por estruturas sociais] em curso e que se desenrolam em contextos e processos específicos". Os autores também argumentam sobre a revisão da estrutura social como pré-existente e delimitadora da ação humana, e sustentam que quadros teóricos elaborados unicamente a partir da Teoria da Estruturação de Giddens não são suficientes para problematizar a agência em contabilidade sob o prisma de prática social em organizações, pois esta privilegia o agente (e a determinação) individual em relação à determinação estrutural.

Assim sendo, a proposta de Sauerbronn e Faria (2012) é que os estudos utilizem uma perspectiva mais pluralista da prática social em adição aos conceitos de codeterminação para estudar agência e reconhecer na pesquisa em contabilidade tanto o lado humano quanto a agência das organizações. Pela codeterminação reconhece-se a agência como um fenômeno que se movimenta por diferentes níveis, de forma que pela análise estratificada se "reconheça simultaneamente as predisposições individuais" de forma que "a agência do gerente, a agência da organização e a agência do ambiente possam ser simultaneamente analisadas" (Sauerbronn \& Faria, 2012, p.12).

A partir das perspectivas oferecidas por estes autores - Wiseman, Cuevas-Rodríguez \& Gomez-Mejia, 2012; e Sauerbronn \& Faria, 2012 - para considerar as relações de agência, os pesquisadores em contabilidade têm a possibilidade de aprofundar a compreensão dos fenômenos que envolvem a contabilidade para além da perspectiva econômica. Um olhar que contemple aspectos relacionados à complexidade institucional e seu contexto repensando conceitos e limitações da teoria de agência, ou um olhar que considere os fenômenos contábeis como práticas sociais construídas e repense ação e co-determinação, pode descortinar novos entendimentos sobre as questões que envolvem agência. 


\section{PESQUISAS PUBLICADAS EM PERIÓDICOS NO BRASIL}

Considerando a inserção da Teoria da Agência no contexto de pesquisas em contabilidade, torna-se relevante observar o que os pesquisadores brasileiros estão pesquisando em Contabilidade Gerencial sob o respaldo dessa teoria. Desta forma, buscou-se apresentar nessa seção as características dos estudos em Contabilidade Gerencial, publicados em periódicos nacionais, que utilizam-se desta teoria .

Uma busca no Portal CAPES, orientada por alguns critérios de seleção, permitiu a análise de oito artigos que utilizam a Teoria da Agência em Contabilidade Gerencial. A seguir, detalha-se os procedimentos utilizados para se chegar aos artigos analisados:

1. Critério utilizado para o primeiro filtro - revistas listadas na Base QualisCapes (Área de Avaliação: Administração, Ciências Contábeis e Turismo) que contenham no título o termo "cont" ou "count". Retornaram 73 revistas (entre nacionais e internacionais). Foram excluídas da análise revistas que tinham como foco comunicações, saúde ou outros temas que não contabilidade, e revistas internacionais.

2. Critério utilizado para o segundo filtro - Revistas classificadas no Qualis Capes triênio 2015-2017 nos estratos $A 1, A 2, B 1, B 2, B 3$. Este segundo filtro retornou 34 revistas nacionais.

3. Para acessar os artigos, entrou-se no site de cada um desses periódicos nacionais (no mês de setembro de 2015) e digitou-se nos espaços de busca da revista os termos: agência; Contabilidade Gerencial. Estes periódicos nacionais retornaram 55 artigos.

4. Dos 55 artigos apenas oito participaram da análise, porque os demais embora tivessem sido selecionados pelas palavras-chave agência e Contabilidade Gerencial não eram artigos que tratavam da Teoria da Agência em Contabilidade Gerencial. A exclusão dos artigos se deu após verificação mediante leitura do resumo e da introdução e, em alguns casos, dos tópicos do referencial teórico.

A Figura 2 mostra em torno de que objetivos a Teoria da Agência tem sido utilizada no Brasil. Também apresenta alguns aspectos metodológicos destas pesquisas. Os conceitos de metodologia e método utilizados nesta pesquisa para enquadrar os artigos são os conceitos apresentados por Ahrens e Chapman (2006, p. 822); os métodos foram classificados considerando a lista utilizada pela pesquisa de Hesford, Lee, Van der Stede, e Young (2007). 


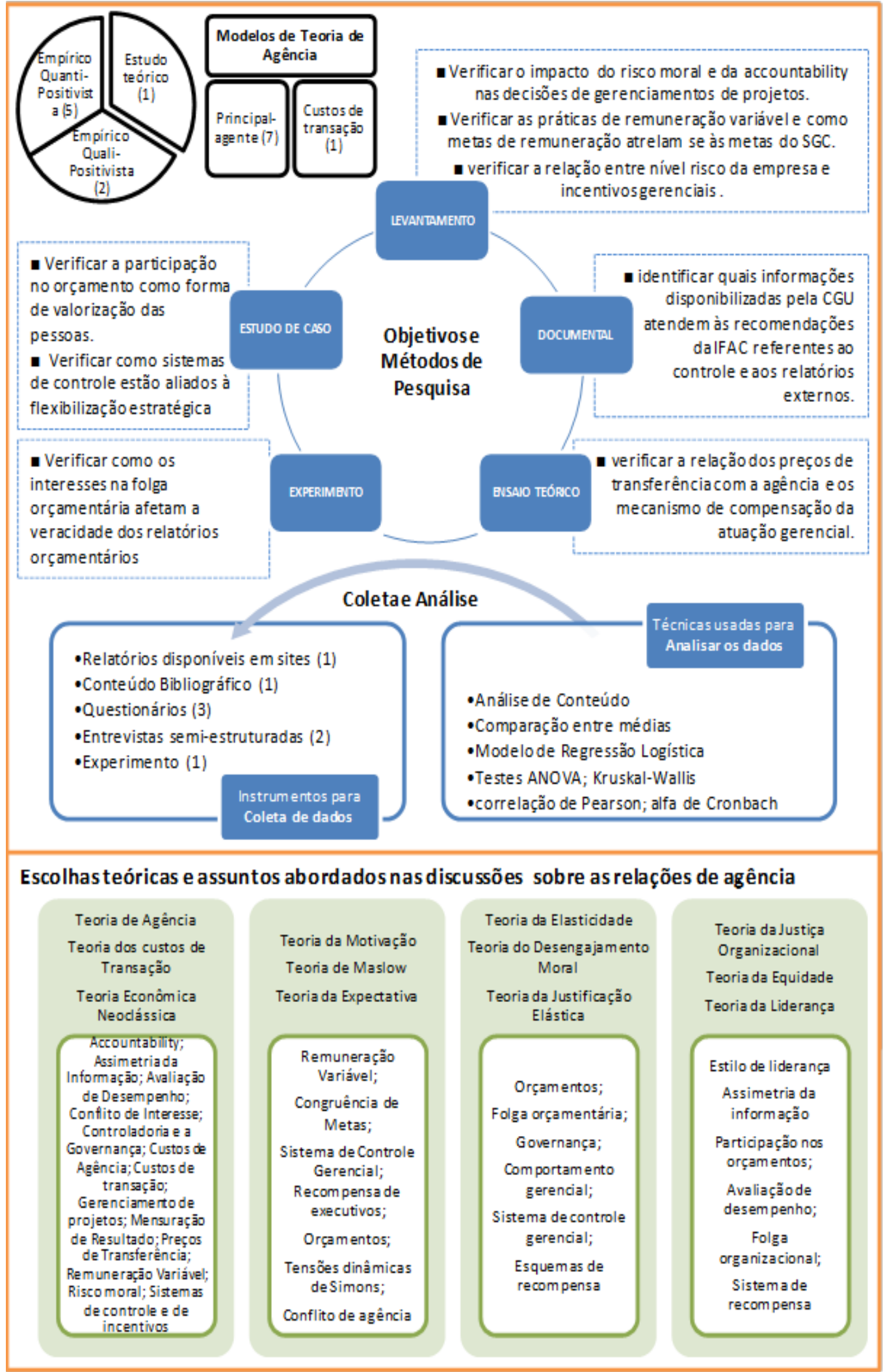


Nos artigos analisados, inclusive aqueles que se autodefinem como de abordagem qualitativa, não são adotadas perspectivas interpretativas ou críticas para a investigação dos fenômenos estudados. Seguindo a classificação proposta por Guba e Lincoln (1998) para pesquisas qualitativas, estes textos se inserem dentro do paradigma positivista. Igualmente, os textos que adotam uma abordagem quantitativa são enquadrados no paradigma mainstream positivista, seguindo a classificação apresentada por Ryan, Scapens e Theobald (2002).

O texto de Jensen e Meckling (1976) é parte da base teórica de cinco artigos analisados. Dos oito artigos analisados, três deles buscam analisar as relações de agência a partir de outras teorias que não propriamente a Teoria da Agência. Esses pesquisadores lançam mão de teorias comportamentais e psicológicas (por exemplo, motivação, expectativa, equidade, engajamento moral) para entender questões relacionadas a orçamentos e congruência de metas. No entanto, as ênfases parecem não se deslocar de aspectos que tangenciam principal-agente, e não contemplam aprofundamentos relacionados aos mecanismos sociais (instituição, cognição, redes de trabalho e poder) como sugerem Wiseman, Cuevas-Rodríguez \& Gomez-Mejia (2012), nem tão pouco co-determinação e agência organizacional como sugerem Sauerbronn e Faria (2012).

Quando se considera os modelos apresentados por Baiman (1990) é possível observar que sete artigos tem seu foco no modelo principal-agente e buscam estudar, por exemplo, sistemas de monitoramento, de orçamento, preços de transferência, e maneiras de os sistemas de controle mitigarem problemas de agência, e um artigo, embora também mencione a Teoria da Agência no seu referencial teórico, apresenta a teoria dos custos de transação e aborda as relações contratuais entre firmas.

Em relação à pergunta "quem é o agente?", os artigos analisados seguem a definição da Teoria da Agência para as ações, tanto dos agentes quanto do principal. Nesse sentido, as pesquisas analisadas consideram certa previsibilidade nos comportamentos de agente e principal, dados os pressupostos da ação humana subjacentes à Teoria utilizada. E além disso, as pesquisas desconsideram a cognoscividade dos agentes e a capacidade de fazer diferente ao interpretar regras, regulamentos e contratos, conforme sugerem Wiseman, Cuevas-Rodríguez \& Gomez-Mejia (2012)

Em relação à pergunta "como são as relações de poder?", percebe-se a manutenção de uma perspectiva top-down nas relações de poder, sendo estas garantidas pelos contratos. Desconsidera-se, nesse sentido, a existência de formas de exercício formal e informal de poder pelo controle de recursos não-financeiros por indivíduos em diversas posições e instâncias nas organizações, conforme sugere Ogden (1993).

Em relação à pergunta "quais são os níveis de análise?", os estudos lidam frequentemente com categorias de análise oriundas do nível organizacional, como: nível de risco e incentivos gerenciais; preços de transferência e mecanismos de compensação; folga orçamentária e veracidade dos relatórios; sistemas de controle e flexibilização. Desconsidera-se nesse sentido a possibilidade de problematizar a co-determinação pelos níveis micro-individuais e macro-estruturais e suas influências nas decisões tidas como racionais e controladas no nível meso-organizacional, como sugerem Sauerbronn e Faria (2012).

Logo, nenhum dos artigos analisados se utilizou de autores ou teorias advindas da sociologia para discutir os problemas de agência. Em geral as pesquisas não discutem em profundidade os pressupostos teóricos em torno do conflito de agência, e em alguns casos, frases curtas citam sinteticamente os pressupostos da teoria utilizada. Nenhuma das pesquisas analisadas destaca as limitações para se aplicar a Teoria da Agência, as limitações apresentadas normalmente referem-se a aspectos relacionados à coleta 
de dados ou amostragem utilizada. De maneira geral, as pesquisas não voltam a problematizar, de forma aprofundada, o conflito de agência nas conclusões do trabalho.

Estes achados corroboram pesquisas como as realizadas por Theóphilo e ludícibus (2005), Nascimento, Junqueira e Martins (2010) e Martins e Zanchet (2012), as quais mostram que tem sido predominante na área de Contabilidade Gerencial no Brasil o paradigma positivista/funcionalista e, a baixa utilização de teorias para explicar a realidade empírica.

Frezatti, Nascimento e Junqueira (2009) chamam a atenção para a necessidade de profundidade metodológica nas pesquisas em Contabilidade Gerencial e argumentam que utilizar apenas o monoparadigma econômico pode ser limitador e nocivo para o desenvolvimento da Contabilidade Gerencial no Brasil. A partir dos argumentos destes autores, pode-se afirmar que, quando problemas de agência são estudados somente pela lente da economia neoclássica, as pesquisas não contribuem para o aprofundamento qualitativo da área.

\section{TEORIA DA AGÊNCIA EM CONTABILIDADE GERENCIAL}

Ryan, Scapens e Theobald (2002, p. 90) discorrem que a inserção de teorias sociais em pesquisas contábeis tem sido sobremaneira significante e que as teorias advindas da sociologia para interpretar questões da contabilidade já tem permitido a reavaliação da história da contabilidade, além de mostrar sua natureza interessada e desafiar reivindicações de neutralidade e racionalidade.

Mesmo com tal ganho e aprofundamento teórico e prático permitido pelas teorias sociais, seu uso em pesquisas de Contabilidade Gerencial ainda ocorre de forma incipiente. Neste sentido torna-se importante considerar a argumentação de Armstrong (1991, p. 19), o qual discorre que a Teoria de Agência sob uma base funcionalista é estática, limitada e tem produzido "nada mais do que um acréscimo ao volume existente de análise funcional dos sistemas de monitoramento e incentivo contábil". Em decorrência disso o autor sugere uma perspectiva histórica e processual da organização na qual seja dada atenção ao conceito de "relação de agência" para entender a contabilidade como articuladora de poder.

Cônscio das forças presentes nas relações de agência, Armstrong (1991, p. 20) destaca que a preocupação central de uma teoria radical de agência não deve estar em "exigências funcionais do controle de cima para baixo". Nesse sentido o autor argumenta que teorias radicais de agência precisam direcionar suas preocupações para "as contradições envolvidas nas tentativas de estabelecer relações de agência efetivas e estáveis dentro da ordem social capitalista e com a localização da contabilidade dentro dessas contradições".

Esse desenvolvimento, na concepção de Armstrong (1991), requer que a relação de agência seja interpretada como algo constituído pela ação social em vez de construído por entidades contábeis e econômicas objetivas. A Tabela 3 sintetiza diferenças cruciais entre uma teorização de agência de base funcionalista e uma teorização com abordagem crítica. 
Tabeça 3: Teorias de agência funcionalistas e radical

\begin{tabular}{|c|c|c|}
\hline & Teoria da agência funcionalista & Teoria da agência radical \\
\hline * Epistemologia & $\begin{array}{l}\text { - Visão positivista de estruturas e entidades } \\
\text { econômicas; } \\
\text { - Estruturas sociais mais amplas são ignoradas. }\end{array}$ & $\begin{array}{l}\text { - Estruturas e entidades econômicas são } \\
\text { construídas socialmente. } \\
\text { - Estruturas mais amplas do capitalismo são } \\
\text { assumidas }\end{array}$ \\
\hline * Metodologia & - Hipotético / preditivo, dados quantitativos. & - Interpretativa. \\
\hline * Visão da Ação social & - Determinista - homem econômico. & $\begin{array}{l}\text { - Ação social baseada em significados. } \\
\text { - Relacionado a interesses como ideologia. }\end{array}$ \\
\hline *Imagem da organização & - Sistema de Contratos & - Sistema de Controles \\
\hline * Meios de controle disponíveis & $\begin{array}{l}\text { - Sistemas de incentivo e monitoramento } \\
\text { baseados em contabilidade. }\end{array}$ & $\begin{array}{l}\text { - Incentivos, monitoramento e confiança } \\
\text { socialmente produzida. }\end{array}$ \\
\hline * Visão dos processos organizacionais & $\begin{array}{l}\text { - Negociação de contratos. } \\
\text { - Reações determinadas por termos contratuais. }\end{array}$ & $\begin{array}{l}\text { - Política complexa de seleção e alocação de } \\
\text { confiança. }\end{array}$ \\
\hline * Custos de agência & $\begin{array}{l}\text { - Vínculo, custos de monitoramento e residual } \\
\text { da incompatibilidade das políticas dos agentes e } \\
\text { Interesses dos principais. }\end{array}$ & $\begin{array}{l}\text { - Os custos da agência incluem a produção } \\
\text { social de confiança. }\end{array}$ \\
\hline * Problemática & - Preocupada com meios de controlar agentes. & $\begin{array}{l}\text { - Preocupado com análise de contradições no } \\
\text { meio de controlar agentes. }\end{array}$ \\
\hline
\end{tabular}

Traduzido de Armstrong (1991, p. 20)

As autoras do presente estudo entendem que, para contemplar uma teorização de agência em contabilidade que privilegie um arcabouço sociológico e mais crítico, tal como o sugerido por Armstrong (1991), os pesquisadores brasileiros que investigam a área contábil, especialmente a contabilidade gerencial, poderiam, por exemplo, considerar a complexidade da ação social para entender os problemas de agência a partir dos conceitos de agência oferecidos por Anthony Giddens e Pierre Bourdieu. As relações de agência e as relações de poder são tratadas por estes teóricos de forma diferenciada e aprofundada em relação ao que se encontra na teorização de agência sob uma base funcionalista.

Para Giddens (1984) a agência, mais do que ser resultado de motivação consciente e autointeressada como pressupõe a economia neoclássica, é resultante tanto das competências quanto das habilidades sociais dos indivíduos, e esta agência ocorre a partir da interação entre comunicação, poder e sanção. Para Bourdieu $(1990,2001)$ os agentes fazem parte de um campo de poder em contínuo conflito e suas ações e representações - e consequentemente agência - derivam do habitus, um princípio forjado pela história que gera as práticas sociais. A força de um agente depende do volume e dos diferentes tipos de capitais (econômico, social cultural) que ele possui.

No contexto internacional alguns pesquisadores (e.g. Smith, 2011; Malmi \& Granlud, 2005; Scapens, 2008) destacam que, de maneira geral, as pesquisas em contabilidade, tanto financeira quanto gerencial, ainda têm contribuído pouco para a prática ou para o desenvolvimento da teoria contábil, e além disso, as teorias alternativas são pouco exploradas pelos pesquisadores contábeis, igualmente não o são os links entre teoria e prática.

Malmi e Granlud (2005) desenvolvem o argumento de que, especificamente, em Contabilidade Gerencial a teoria liga-se à pratica de maneira frágil, e ao advogarem pela busca do conhecimento de interesse técnico defendem a tese de que as pesquisas dentro da CG devem permitir uma explicação que seja útil e que dê suporte aos praticantes da contabilidade.

Nesse sentido, considerando o perfil encontrado nas pesquisas brasileiras em Contabilidade Gerencial sobre teoria da agência e as possibilidades descortinadas pela sociologia para compreender as relações de agentes e relações de poder, pode-se dizer que repensar problemas de agência nas pesquisas em Contabilidade Gerencial no Brasil, a partir das lentes das teorias sociais, consiste em uma alternativa teórica e metodológica significativa para expandir o entendimento dos fenômenos contábeis que giram em torno de delegação, controle e governança. 


\section{CONSIDERAÇÕES FINAIS}

O objetivo deste estudo foi propor uma reflexão sobre como as pesquisas em contabilidade utilizam teorias e de maneira especial como a Teoria da Agência é utilizada, considerando suas premissas, limitações e formulações alternativas aos seus pressupostos. A discussão buscou inicialmente mostrar que a Teoria da Contabilidade normalmente não é utilizada sozinha pelos pesquisadores, mas vincula-se à teorias de outras áreas para sustentar o estudo dos fenômenos contábeis, tanto em pesquisas financeiras quanto gerenciais.

A Teoria da Agência foi apresentada a partir de três vertentes principais, as quais consideram o autointeresse do agente e os problemas de agência decorrentes de comportamento não cooperativo, razões pelas quais muitos críticos apresentam objeções que giram em torno de questões como: oportunismo do agente, busca de solução ótima, assimetria unilateral, simplicidade de modelos e complexidade de fenômenos, e não consideração das relações de poder. Os argumentos apresentados no corpo deste artigo permitem refletir sobre ao menos três questões cruciais no que concerne à teorização sobre agência:

Quem é o agente? Para a perspectiva tradicional da Teoria da Agência, baseada na economia neoclássica, o agente é autointeressado, sempre agirá em benefício próprio, possui informações ocultas ao principal e por isso deve ser sempre monitorado. Para estudar agência orientada por teorias sociais este agente não agirá necessariamente em benefício próprio, ele poderá, por exemplo, compartilhar com o principal a característica de potencial para ação autointeressada, e ambos podem ter um comportamento oportunístico.

Como são as relações de poder? Para a perspectiva tradicional este aspecto não é explorado nos modelos de análise, de outro lado a Teoria da Agência sob uma perspectiva sociológica conforme sugerida por Wiseman, Cuevas-Rodríguez e Gomez-Mejia (2012) considera as relações de poder como parte do contexto institucional que molda os papéis de agente e principal e influencia os problemas de agência. Ainda sob uma perspectiva sociológica, ao considerar agência a partir dos conceitos teóricos propostos por Anthony Giddens e Pierre Boudieu, o agente é dotado de competências, habilidades sociais e capitais que são fundamentais para moldar da ação. Ambos os teóricos reconhecem as relações de poder em torno da ação e reconhecem a capacidade de o agente modificar as circunstâncias, embora para Bourdieu o agente e sua ação estejam mais limitados às questões culturais

Como são os níveis de análise? A perspectiva tradicional oferece modelos de análise que permitem explorar as relações proprietário-gerente ou gerente-trabalhador e os mecanismos de controle para mediar aspectos inerentes a essa relação. Por outro lado, a relação de agência sob uma perspectiva de prática social conforme sugerido por Sauerbronn e Faria (2012) adiciona elementos de codeterminação para explorar a agência não apenas dos indivíduos, mas também da organização, de maneira que o nível meso-organizacional passa a ser considerado como elemento fundamental na análise, bem como os jogos de poder entre grupos internos e aspectos advindos da cultura organizacional.

Refletir sobre estes três elementos - agente, relações de poder, níveis de análise - leva à percepção de que utilizar uma abordagem alternativa à formulação econômica de agência pode gerar insights significativos para o contexto brasileiro. Além disso o artigo mostrou que as pesquisas em Contabilidade Gerencial no Brasil, embora utilizem a Teoria da Agência, não aprofundam seus aspectos teóricos nos achados de pesquisa. Nesse sentido, sugere-se que os pesquisadores em Contabilidade Gerencial utilizem outras teorias para discutir profundamente diferentes contextos organizacionais e considerem explorar agência sob as lentes alternativas da sociologia como as apresentadas neste texto. 


\section{REFERÊNCIAS}

Ahrens, T., \& Chapman, C. S. (2006). Doing qualitative field research in management accounting: Positioning data to contribute to theory. Accounting, Organizations and Society, 31, pp. 819-841.

Armstrong, P. (1991). Contradiction and Social Dynamics in the Capitalist Agency. Accounting, Organizations and Society, 16(1), pp. 1-25.

Baiman, S. (1990). Agency Research in Managerial Accounting: A Second Look. Accounting, Organizational and Society, 15(4), pp. 341-371.

Beattie, V. (2002). Traditions of research in financial accounting. In B. Ryan, R. W. Scapens, \& M. Theobold, Research Method and Methodology in Finance and Accounting (pp. 94-116). London: Cengage Learning.

Bogt, H. T., \& Helden, J.V. (2012). The practical relevance of management accounting research and the role of qualitative methods therein: The debate continues. Qualitative Research in Accounting \& Management, 9(3), pp. 265-273.

Bourdieu, P. (1990). The Logic of Practice. Redwood City: Stanford University Press, 1990.

Bourdieu, P. (2001). Para uma sociologia da ciência. Lisboa: Edições 70.

Bromwich, M. (2007). Economics in Management Accounting. In: C. S. Chapman, A. G. Hopwood, \& M. D. Shielsd, Handbook of Management Accounting Research (pp. 137-162). Oxford, UK: Elsevier.

Burns, J., \& Scapens, R. W. (2000). Conceptualizing management accounting change: an institutional framework. Management Accounting Research, 11, pp. 3-25.

Chenhall, R. H. (2007). Theorizing Contingencies in Management Control Systems Research. In: C. S. Chapman, A. G. Hopwood, \& M. D. Shields, Handbook of Management Accounting Research (pp. 163205). Oxford, UK: Elsevier.

Davis, S. W., Menon, K., \& Morgan, G. (1982). The images that have shaped accounting theory. Accounting, Organizations and Society, 7(4), pp. 307-318.

Frezatti, F., Nascimento, A. R., \& Junqueira, E. (2009). Desenvolvimento da pesquisa em contabilidade gerencial: as restrições da abordagem monoparadigmatica de Zimmerman. Revista Contabilidade e Finanças, 20(49), 6-24.

Giddens, A. (1984) Elements of the Theory Structuration. In: Giddens, A. The Constitution of Society: Outline of the Theory of Structuration. Berkeley and Los Angeles: University of California Press, p. 1-39.

Guba, E. G., \& Lincoln, Y. S. (1998). Competing Paradigms in Qualitative Research. In: N. K. Denzin, \& Y. S. Lincoln, The Landscape of Qualitative Research:Theories and Issues (pp. 195-220). Sage Publications.

Hendriksen, E. S., \& Van Breda, M. F. (2007). Introdução e Metodologia da Contabilidade. In: E. S. Hendriksen, \& M. F. Van Breda, Teoria da Contabilidade (pp. 21-35). São Paulo: Atlas.

Hesford, J. W.; Lee, S.H.; Van der Stede, W. A.; Young, S. M. (2007). Management Accounting: A Bibliographic Study. In: C. S. Chapman, A. G. Hopwood, \& M. D. Shields, Handbook of Management Accounting Research (pp. 3-26). Oxford, UK: Elsevier.

ludícibus, S. d., Martins, E., \& Carvalho, L. N. (Maio/Ago de 2005). Contabilidade: Aspectos relevantes da epopéia de sua evolução. R. Cont. Fin. - USP, 38, pp. 7-19.

Jackson, M. C. (1999). Towards Coherent Pluralism in Management Science. The Journal of the Operational Research Society, 50(1), pp. 12-22.

Lambert, R. A. (2007). Agency Theory and Management Accounting. In C. S. Chapman, A. G. Hopwood, \& M. D. Shields, Handbook of Management Accounting Research - Volume 1 (pp. 247-268). Oxford, UK: Elsevier.

Laughlin, R. (1995). Methodological themes Empirical research in accounting: alternative approaches and a case for"middle-range"thinking. Accounting, Auditing \& Accountability Journal, v. 8, n. 1, p. 63-87. 
Lourenço, R. L., \& Sauerbronn, F. F. (2015). Revistando possibilidades epistemológicas em contabilidade gerencial: em busca de contribuições de abordagens interpretativas e críticas no Brasil. Revista Contemporânea de Contabilidade, Florianópolis, 13(28), pp. 99-122.

Malmi, T., \& Granlud, M. (2009). In search of Management Accounting Theory. European Accounting Review, 18(3), 597-620.

Martins, G. d., \& Zanchet, A. (2012). Sobre a complexidade dos achados de pesquisas contábeis. Anais do Colóquio Internacional de epistemologia e sociologia da ciência da administração, 2. Florianópolis, SC, Brasil.

Modell, Sven. (2010). Bridging the paradigm divide in management accounting research: The role of mixed methods approaches. Management Accounting Research, 21, 124-129.

Modigliani, F., \& Miller, M. H. (1958, jun). The Cost of Capital, Corporation Finance and the Theory of Investment. The American Economic Review, pp. 48 (3), 261-297.

Nascimento, A. R., Junqueira, E., \& Martins, G. d. (2010). A pesquisa acadêmica em contabilidade gerencial no Brasil: análise e reflexões sobre teorias, metodologias e paradigmas. RAC, 14(6), 1113-1133.

Ogden, S. (1993). The limitations of Agency Theory: the case of accounting-based profit sharing schemes. Critical Perspectives on Accounting, 4, pp. 179-206.

Ryan, B., Scapens, R. W., \& Theobald, M. (2002). Traditions of research in management accounting. In B. RYAN, R. W. SCAPENS, \& M. THEOBALD, Research Method and Methodology in Finance and Accounting (pp. 68-93). London: Wouth Wester: Cengage Learning.

Sauerbronn, F. F., \& Faria, A. (2012). Pluralismo no Estudo da Agência em Contabilidade: Contribuições da Perspectiva da Prática Social. Congresso Nacional de Administração e Ciências Contábeis - AdCont 2012, III. Rio de Janeiro/RJ.

Smith, M. (2011). Research Methods in Accounting. London: SAGE Publications.

Scapens, R. W. (2008) Seeking the relevance of interpretive research: A contribution to the polyphonic debate. Critical Perspectives on Accounting, 19, pp. 915-919.

Taipaleenmäki, J., \& Ikäheimo, S. (2013). On the convergence of management accounting and financial accounting: the role of information technology in accounting change. International Journal of Accounting Information Systems, 14, pp. 321-348.

Theóphilo, C. R., \& ludícibus, S. D. (2009). Uma análise crítico-epistemológica da produção científica em contabilidade no Brasil. Contabilidade, Gestão e Governança, 8.

Watts, R. L., \& Zimmerman, J. L. (1979, april). The Demand for and Supply of Accounting Theories: The Market for Excuses. The Accounting Review, 4 (2), pp. 273-305.

Waweru, N. M. (2010). The origin and evolution of management accounting: a review of the theoretical framework. Problems and Perspectives in Management, 8(3), pp. 165-182.

Wheten, D. (2003). O que constitui uma contribuição Teórica. RAE, 43(3), pp. 69-73.

Wiseman, R. M., Cuevas-Rodríguez, G., \& Gomez-Mejia, L. R. (2012). Towards a Social Theory of Agency. Journal of Management Studies, 49(1), pp. 202-222. 